\title{
Standardisation efforts of ISO/TC 261 "Additive Manufacturing": Reports from 14th and 15th Plenary Meeting
}

\author{
Eujin Pei ${ }^{1}$ (D)
}

Received: 28 May 2020 / Accepted: 7 July 2020 / Published online: 20 July 2020

(c) The Author(s) 2020

\begin{abstract}
The main objective of ISO/TC 261 is to standardise the processes of Additive Manufacturing, the process chains (Data, Materials, Processes, Hard- and Software, Applications), test procedures, quality parameters, supply agreements, environment, health and safety, fundamentals and vocabularies. The technical contents for those standards are developed in different Working Groups of ISO/TC 261. This section provides readers with news regarding standardisation efforts of ISO/TC 261.
\end{abstract}

Keywords Standardisation · Standards · Additive manufacturing

\section{New joint groups}

1. Establishment of ISO/TC 261/JG 78 "Safety regarding AM-machines (relating to harmonized European Standards, Type C-Standard)" with the following scope: "ISO/ TC $261 /$ JG 78 is a Joint group for drafting safety standards for additive manufacturing machines used for the seven process categories as identified in ISO 17296-2 and using all different types of materials (e.g. metals, polymers and ceramics) as feedstock. The purpose of this group is to draft standards to be harmonized regarding the European Machinery Directive in order to give presumption of conformity to this Directive for the essential requirements covered by the standard." ISO/ TC $261 / \mathrm{JG} 78$ would be allocated to parent committees ISO/TC 261/WG 6 and ASTM F42 06 [1].

2. Establishment of ISO/TC 261/JWG 12 "Joint ISO/TC 261-ISO/TC $150 \mathrm{WG}$, Additive manufacturing in surgical implants" with the following scope: "Standards (i.e., development of new standard(s) and revising existing standards) to address critical factors in the field of additive manufacturing in surgical implant applications [1]".

3. Establishment of ISO/TC 261/AHG 6 "Coordination of work between ISO/TC 261 and ISO/TC 184/SC 1

Eujin Pei

eujin.pei@brunel.ac.uk

1 Brunel University London, Uxbridge, UK and ISO/TC 184/SC 4" with the following scope: "The ad-hoc group has the specific scope of facilitating communication between ISO/TC 261 and ISO/TC 184/SC 1 and ISO/TC 184/SC 4. It is expected to act to ensure the absence of overlapping between the activities of these TCs promoting early stage bidirectional communication on ongoing and new projects [1]".

\section{New projects}

1.Preliminary work item ISO/ASTM NP 52930 "Guideline for Installation/Operation/Performance Qualification (IQ/OQ/PQ) of Laser-Beam Powder Bed Fusion Equipment for Production Manufacturing" assigned to ISO/TC 261/JG 72 and registered as a joint ISO/ASTM standards project [2].

2. Preliminary work item ISO/ASTM NP 52935 "Additive manufacturing-Qualification principles-Qualification of coordinators for metallic parts production" assigned to ISO/TC 261/JG 74 and registered as a joint ISO/ASTM standards project [2].

3. Preliminary work item ISO/ASTM PWI 52937 "Additive manufacturing-Qualification principles-Qualification of Designer for metallic parts production" assigned to ISO/TC 261/JG 74 and registered as a joint ISO/ASTM standards project [2].

4.Preliminary work item ISO/ASTM PWI 52938-1

"Additive manufacturing-Environmental Health and Safety-Part 1: Safety requirements for PBF-LB machine 
using metallic feedstock" assigned to ISO/TC 261/JG 78 and registered as a joint ISO/ASTM standards project [1].

\section{Projects due for ballot}

1. Two projects being finalised by ISO/TC $261 / \mathrm{JWG} 5$ "Joint ISO/TC 261-ISO/TC 44/SC 14 WG, Additive manufacturing in aerospace applications" for ISO/FDISballot: ISO/ASTM DIS 52941 "Additive manufacturing-System performance and reliability-Standard test method for acceptance of powder-bed fusion machines for metallic materials for aerospace application"; and ISO/ASTM DIS 52942 "Additive manufacturing-Qualification principles-Qualifying machine operators of laser metal powder bed fusion machines and equipment used in aerospace applications" [2].

\section{Revision of standards}

1.Revision of ISO 27547-1 will be registered as a preliminary work item ISO/ASTM PWI 52936-1 "Additive manufacturing-Qualification principles-Laser based powder bed fusion of polymers-Part 1: General principles, preparation of test specimens" and assigned to ISO/ TC 261/JWG 11 [2].

2.ISO/ASTM 52902 "Additive manufacturing-Test artifacts-Geometric capability assessment of additive manufacturing systems" is due for revision and assigned to ISO/TC 261/WG 3 [2].

\section{Change of title}

1.Changing the numbering of ISO/ASTM PWI 52913 to ISO/ASTM PWI 52913-1 and changing the title to "Additive manufacturing-Test methods for characterization of powder flow properties for AM applications-Part 1: General requirements" [2].

2.Changing the title of ISO/ASTM DIS 52924 "Additive manufacturing-Qualification principles-Quality grades for additive manufacturing of polymer parts" to ISO/ASTM DIS 52924 "Additive manufacturing-Qualification principles-Classification of part properties for additive manufacturing of polymer parts" [2].

\section{Change of scope}

1. Changing the scope of ISO/TC $261 / \mathrm{JG} 77$ "Joint ISO/TC 261-ASTM F 42 Group Test method of sand mould for metal casting" to the following "ISO/TC $261 / \mathrm{JG} 77$ is a Joint group responsible for the standardisation of meth- ods for testing sand moulds made by additive manufacturing technologies. Note: Typical areas for testing sand moulds includes, but is not limited to, bending strength, compression strength, gas permeability, and others" [1].

\section{Cancellation of project}

1. Cancellation of ISO/ASTM PWI 52934 "Additive manufacturing-Environmental health and safety-Standard guideline for hazard risk ranking and safety defense" due to no progress being made in the last 2 years, and the fact that the planned scope is covered by ISO/ASTM AWI 52931 "Additive manufacturing-Environmental health and safety - Standard guideline for use of metallic materials" [1].

Acknowledgements The material and information contained is for general information purposes only. Readers are advised not to rely upon the material or information as a basis for making any business, legal or any other decisions. Whilst the Progress in Additive Manufacturing Journal (PIAM) endeavours to keep the information up to date and correct, PIAM makes no representations or warranties of any kind, express or implied about the completeness, accuracy, reliability, suitability or availability with respect to the information contained in the journal for any purpose.

Funding None.

\section{Compliance with ethical standards}

Conflict of interest None.

Open Access This article is licensed under a Creative Commons Attribution 4.0 International License, which permits use, sharing, adaptation, distribution and reproduction in any medium or format, as long as you give appropriate credit to the original author(s) and the source, provide a link to the Creative Commons licence, and indicate if changes were made. The images or other third party material in this article are included in the article's Creative Commons licence, unless indicated otherwise in a credit line to the material. If material is not included in the article's Creative Commons licence and your intended use is not permitted by statutory regulation or exceeds the permitted use, you will need to obtain permission directly from the copyright holder. To view a copy of this licence, visit http://creativecommons.org/licenses/by/4.0/.

\section{References}

1. International Organisation for Standardisation (2020) 15th Plenary meeting of ISO/TC 261 "additive manufacturing" held on 14 february 2020, El Paso, Texas, USA, ISO/TC 261 N762

2. International Organisation for Standardisation (2019) 14th Plenary meeting of ISO/TC 261 "additive manufacturing" held on 20 september 2019, Senlis, France, ISO/TC 261 N722

Publisher's Note Springer Nature remains neutral with regard to jurisdictional claims in published maps and institutional affiliations. 